\title{
CADMIUM OXIDE THIN FILMS SYNTHESIZED AT LOW TEMPERATURE BY SPRAY CVD TECHNIQUE FOR $\mathrm{H}_{2} \mathrm{~S}$ GAS SENSING APPLICATIONS
}

\author{
C. R. Bobade \\ Department of Physics, Balwant College, Vita, Dist:Sangli-415 311 (MS) India. \\ Email: chandrakant.bobade24@gmail.com
}

\begin{abstract}
:
Cadmium Oxide $(\mathrm{CdO})$ thin films were deposited onto glass at low substrate temperature of $210{ }^{\circ} \mathrm{C}$ using spray CVD technique. The structural, morphological, optical and gas sensing properties of the films were investigated. X-ray diffraction (XRD) studies show that films thus prepared are polycrystalline in nature with rock salt type cubic crystal structure and are preferentially oriented along (111) plane. Scanning Electron Microscopy (SEM) micrographs revealed that the film surfaces were rough and exhibit granular morphology. From optical studies it is seen that the films were transparent in the visible region. The measured values of band gap of as deposited films found to vary from 2.42 to 2.55 eV. $\mathrm{H}_{2} \mathrm{~S}$ gas sensing studies were carried out by using homemade gas sensing equipment and it was observed that a typical sample showed up to $10 \%$ sensitivity at an operating temperature of $250{ }^{\circ} \mathrm{C}$.
\end{abstract}

Keywords: Cadmium Oxide; spray CVD; SEM and gas sensing.

\section{INTRODUCTION:}

Besides the important role played in flat panel displays, solar cells and optoelectronic devices, metal oxides such as $\mathrm{ZnO}[1], \mathrm{WO}_{3}[2], \mathrm{SnO}_{2}$ [3] , $\mathrm{In}_{2} \mathrm{O}_{3}$ [4], $\mathrm{CdO}$ [5], $\mathrm{TiO}_{2}$ [6], are used in gas sensing to detect the gases such as $\mathrm{CO}, \mathrm{CO}_{2}, \mathrm{H}_{2}$ $\mathrm{NH}_{3}, \mathrm{H}_{2} \mathrm{~S}$, LPG and NOx. These gases are toxic causing serious health hazards lead to air pollution extensively and result into environmental effects like green house effect, global warming etc. The gas sensing mechanism of such semiconducting metal oxides is based on change in electrical conductivity with the chemisorbed gas and/or interaction with reabsorbed adions when exposed to the different gases [7]. Till date, a variety of physical and chemical methods have been investigated to synthesize metal oxide thin films. Since the physical and chemical properties of the films depend on the mode of preparation, which necessarily affect the gas-sensing properties. Therefore growth parameters, such as growth temperature, film thickness etc. during the surface formation is of prime importance. The growth/substrate temperature affects the structural and morphological properties of as deposited thin films. Furthermore, the film thickness has direct influence on the resistivity; which is an important factor in resistive type gas sensors [8].

Cadmium oxide $(\mathrm{CdO})$ is a n-type semiconductor and has drawn considerable attention amongst researchers in fabrication of solar cells and optoelectronic devices. However, $\mathrm{CdO}$ is yet to be studied elaborately as a gas sensing material. Among the several metal-oxide gas sensing materials, the role of nanocrystalline $\mathrm{CdO}$ as a gas sensor, needs to be studied specifically [9]. Earlier studies reveal that $\mathrm{CdO}$ has shown response to gases/vapors such as LPG [10]. However, very less attempts have been made to detect reducing gases such as hydrogen sulfide $\left(\mathrm{H}_{2} \mathrm{~S}\right)$ which is one of the noxious, colorless and aromatic gases, ammonia (NH3) etc. Recently attempts have been made to improve the selectivity and response time of these gas sensors [2-6] either by using suitable dopant or with modification in synthesis process. The present study deals with deposition of cadmium oxide films by using spray CVD technique which is an 
augmentation of conventional spray pyrolysis technique [11].

\section{Experimental}

\subsection{TGA-DTA Analysis of Cadmium Acetate}

In order to determine the range of deposition temperature of the furnace / reaction chamber, phase transformations and weight loss occurring during heating, cadmium acetate

$[\mathrm{Cd}$ $\left.\left(\mathrm{CH}_{3} \mathrm{COO}\right) 2 \cdot 2 \mathrm{H}_{2} \mathrm{O}\right]$ powder was subjected to simultaneous thermo-gravimetric (SDT-Q600 V20.9 Build 20) and differential thermal analysis (TA Instruments). Fig.1 represents the thermogram recorded for cadmium acetate powder. It was reported that [12] the thermal evolution in air atmosphere occurs in four successive steps with weight losses corresponding to which the inflection point overlaps with the temperature corresponding to the endotherms and exotherms in DTA trace.

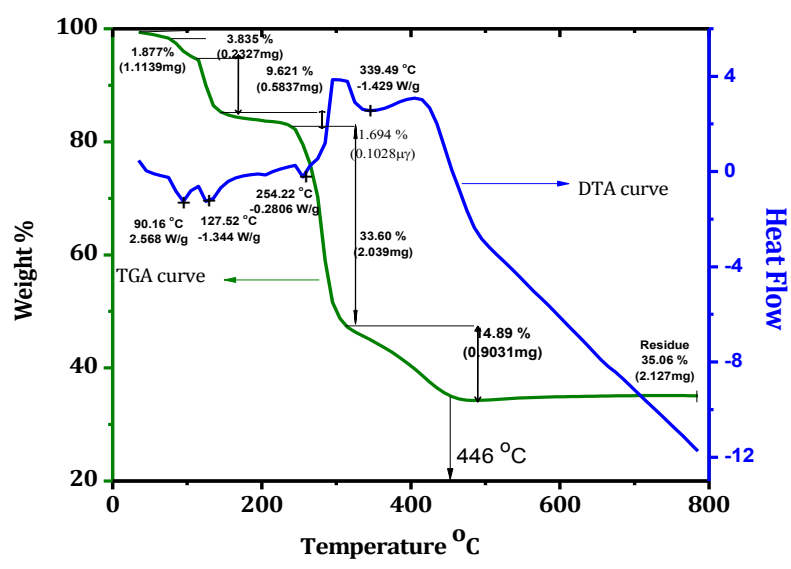

Fig.1. TGA / DTA analysis of cadmium acetate

The weight loss of cadmium acetate begins at $75^{\circ} \mathrm{C}$. To begin with, the minor weight loss in the temperature range $75^{\circ}-100^{\circ} \mathrm{C}$ due to removal of one of the water molecule in the precursor was reported, the second water molecule is removed at $130^{\circ} \mathrm{C}$ and the TGA curve slowly decays from $100-150^{\circ} \mathrm{C}$. Abrupt weight loss was found in the range $235^{\circ}$ $315^{\circ} \mathrm{C}$ where acetate group is removed completely. And a stable $\mathrm{CdO}$ phase existed up to $800{ }^{\circ} \mathrm{C}$ [12].
The overall reaction taking place inside the furnace may be expressed as [13] :

$$
\begin{aligned}
& \mathrm{Cd}\left(\mathrm{CH}_{3} \mathrm{COO}\right)_{2}+3 \mathrm{H}_{2} \mathrm{O} \stackrel{\Delta}{\rightarrow} \mathrm{CdO} \text { solid }+4 \mathrm{H}_{2} \uparrow+ \\
& \left(\mathrm{CH}_{4}\right) \uparrow+3\left(\mathrm{CO}_{2}\right) \uparrow
\end{aligned}
$$

\subsection{Deposition of Cadmium Oxide Thin Films}

Pure $\mathrm{CdO}$ thin films were synthesized using spray CVD technique reported elsewhere. A pre-optimized $0.02 \mathrm{M}$ aqueous solution of high purity (99.9\%) cadmium acetate (Thomas Baker, India) was prepared in double distilled water to obtain $\mathrm{CdO}$ thin films. The chemical solution was atomized through a glass nozzle and the reactants were allowed to decompose pyrolytically. Metal oxide particles were pushed towards glass substrates mounted above the core of reaction chamber of furnace and deposited on it. During the course of deposition, the nozzle to substrate distance was kept at $37 \mathrm{~cm}$ and compressed air at a pressure of 11 LPM (litre per min.) was maintained to control the solution spray rate at $\sim 6 \mathrm{ml} / \mathrm{min}$. To study the effect of core temperature (reaction chamber temperature) on the CdO film properties, films were deposited by varying the core temperature from 300 $-375{ }^{\circ} \mathrm{C}$ at a step of $25^{\circ} \mathrm{C}$ and by keeping constant substrate temperature. It is found that all films were adherent to the substrate, however, film thickness is low at temperature above $300{ }^{\circ} \mathrm{C}$. This might be due to high kinetic energy of metal oxide oxide particles at higher temperature of reaction chamber. Hence the core temperature of $300{ }^{\circ} \mathrm{C}$ was considered to be optimized temperature for further experiments.

To study the effect of substrate temperature, the other preparative parameters such as air pressure: $11 \mathrm{LPM}$, spray rate: $\sim 6 \mathrm{ml} / \mathrm{min}$, nozzle to substrate distance: $37 \mathrm{~cm}$, reaction chamber temperature $\left(300^{\circ} \mathrm{C}\right)$ were kept constant, and then the solution was atomized through glass nozzle. The resultant aerosols arrive in the reaction chamber and lead to oxidation of the ingredient. The fine particles of the 
pyrolytic reaction product were pushed up and allowed to reach the preheated substrates kept at different temperatures ranging from 190 to $230{ }^{\circ} \mathrm{C}$ at steps of $20{ }^{\circ} \mathrm{C}$. For simplicity, the $\mathrm{CdO}$ films prepared at 190,210 and $230^{\circ} \mathrm{C}$ substrate temperatures were designated as $\mathrm{T}_{190}, \mathrm{~T}_{210}$ and $\mathrm{T}_{230}$, respectively.

Further, to investigate the effect of thickness, films were deposited by varying spray volume of initial solution and keeping all other preparative parameters constant and were designated as V1, V2, V3 and V4 corresponding to spray volumes 100 , 150, 200 and $300 \mathrm{ml}$. respectively.

\subsection{Characterization and Gas Sensing Measurements}

Morphological studies of as-prepared CdO thin films were carried out using a X-ray diffractometer (Bruker D-2 Phaser, Powder XRD made by analytical instruments Pvt. Ltd., Germany) with $\mathrm{Cu}$ Ka radiation having wavelength $1.5406 \AA$. All the diffraction patterns were recorded by varying diffraction angle in the range 20 to $80^{\circ}$ at a step size of $0.1^{\circ}$. Film thickness was measured with the help of AMBIOS-XP-1 surface profilometer. Surface morphology of the CdO thin films, grain size and distribution of grains were examined by a JEOL JSM-6360 scanning electron microscope (SEM). Optical absorption measurements were carried out at room temperature in the spectral range of 300$800 \mathrm{~nm}$ using a UV-VIS spectrophotometer (Shimadzu Japan, 1800 model).

Furthermore, to study the $\mathrm{H}_{2} \mathrm{~S}$ gas sensing performance, $\mathrm{CdO}$ films were mounted in an airtight housing having a volume of $250 \mathrm{~cm}^{3}$. The electrical contacts onto the film surfaces at distance of $1 \mathrm{~cm}$ were made using silver paste (Alpha Aesar). A measured quantity of well calibrated gas concentration (ppm) was introduced in the housing using highly calibrated syringe and change in resistance of the sample under study was measured as a function of time. The "Rigol DM3062 model" digital multimeter/ data acquisition system was used to measure the electrical resistance of the films before and after exposure to $\mathrm{H}_{2} \mathrm{~S}$ gas of known concentration. The film response to $\mathrm{H}_{2} \mathrm{~S}$ gas was measured at different operating temperatures and for various gas concentrations. Percentage gas response $(\% \mathrm{~S})$ was calculated using well kown equation $\% \mathrm{~S}=\left[\left(\mathrm{R}_{\mathrm{a}}-\mathrm{R}_{\mathrm{g}}\right) / \mathrm{R}_{\mathrm{a}}\right] \times 100 \%$, where $\mathrm{R}_{\mathrm{a}}$ is the film resistance in air and $R_{g}$ is the film resistance when exposed to gas to be sensed. The response and recovery times are defined as the time taken by a sensor to achieve $90 \%$ of the total change in resistance from its base line value.

RESULT \& DISCUSSION :

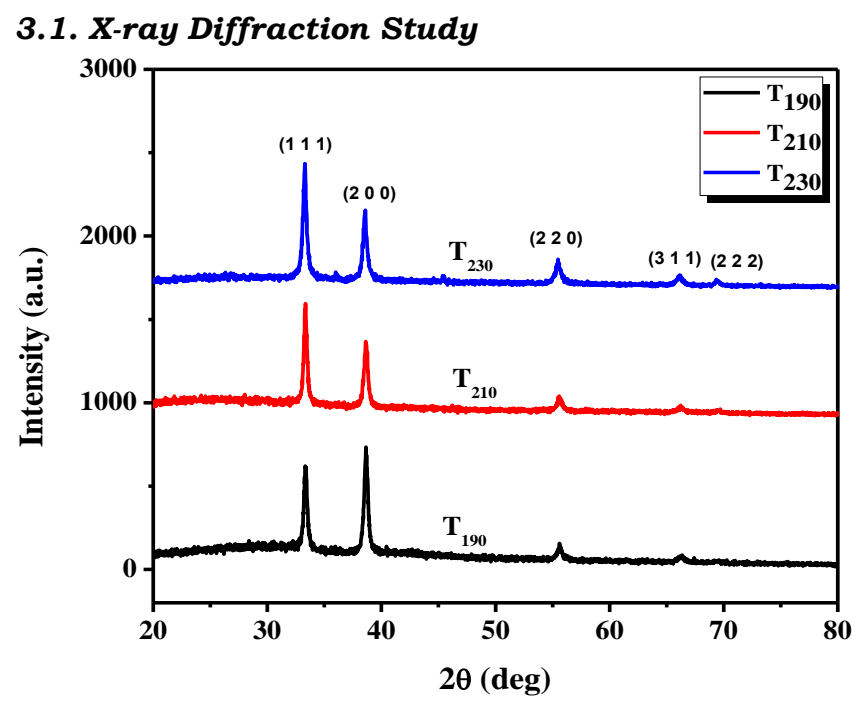

Fig. 2: XRD patterns of CdO thin films prepared at different substrate temperatures.

The average crystallite size (D) of the films was calculated using the Scherrer formula [14, 15]. It is seen that, $\mathrm{CdO}$ films deposited at $210{ }^{\circ} \mathrm{C}$ have average grain size of $\sim 30 \mathrm{~nm}$, while the crystallite size decreases marginally at higher substrate temperatures. This may be attributed to the variation in the optimum movement of particle towards substrate due to excess thermal energy. By considering the crystallite size, $210^{\circ} \mathrm{C}$ substrate temperature was used as optimum substrate temperature and it is used for further study. 


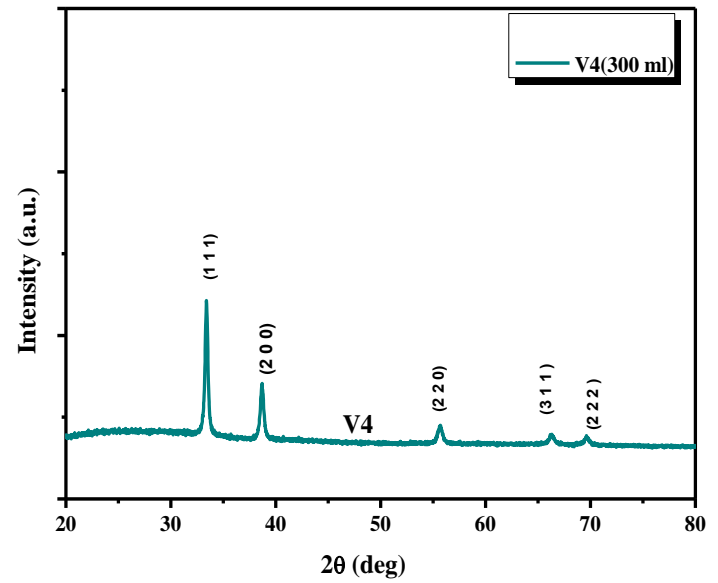

Fig. 3: $X R D$ patterns of typical $\mathrm{CdO}$ thin film prepared at optimized core and substrate temperatures and at $300 \mathrm{ml}$ spray solution.

To study the effect of spray volume on crystalline state, the films with different quantity of spray solution were synthesized. Fig.3. shows the XRD patterns of a typical film grown with $300 \mathrm{ml}$ of spray solution, at substrate temperature of $210{ }^{\circ} \mathrm{C}$. It was observed that crystallographic properties of the $\mathrm{CdO}$ films depend on quantity (volume) of spray solution. XRD pattern of typical sample V4 ( fig.3) shows well-defined (111) peak along with reflections from (200), (220), (311) and (222) planes. The observed " $\mathrm{d}$ " values are found to match with standard "d" values [JCPDS No. 05-0640] reported by Salunkhe et al [14].

\subsection{Morphological Study}

As it is evident that surface properties of the sensor have a great influence on gas sensing performance. For instance, the increase in grain size of the films decreases the surface area to be exposed to the analyte gas and results in decrease in the response of gas sensor. Therefore, it is essential to investigate the surface morphology of the films. Investigation of surface morphology of $\mathrm{CdO}$ thin films was carried out using scanning electron microsopy (SEM).

Fig. 4. exhibits SEM micrograph of the typical sample V4 at magnification of $\mathrm{X} 10000$. It is seen that film surface is rough and further observed that roughness increases with increase in volume of the initial solution ( not shown). This may be attributed to the increase in grain size due to increase in film thickness [10].

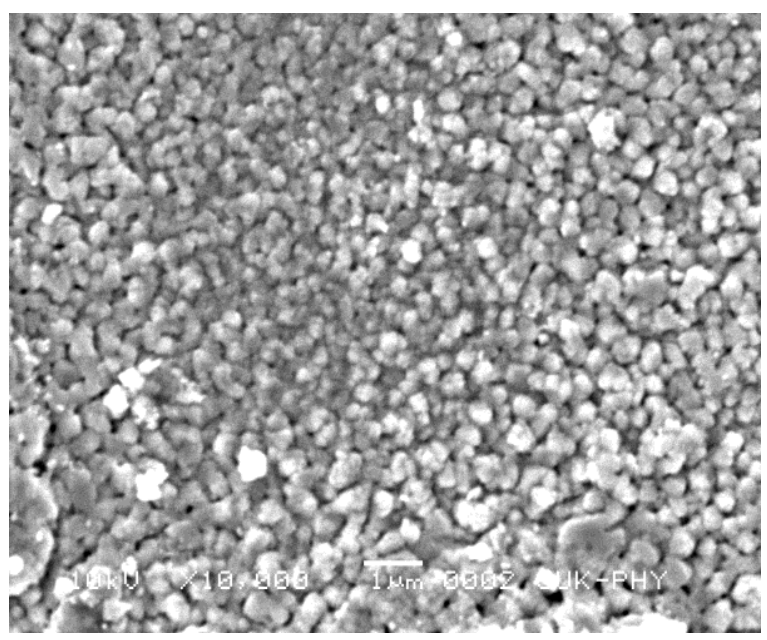

Fig .4: $\quad$ SEM micrographs of sample V4 at magnification of $X 10,000$.

\subsection{Compositional Study}

\subsubsection{Energy Dispersive X-ray (EDAX) Analysis}

The elemental analysis of sample V4 was carried out by means of energy dispersive $\mathrm{x}$-ray analysis (EDAX) with the help of which, atomic percent of the elements deposited from the precursor was analyzed. The EDAX analysis shows the presence of elements as shown in the Table 1, which reveals that $\mathrm{CdO}$ films prepared by spray CVD technique are stoichiometric.

Fig.5.represents the elemental mapping as done by the same method and confirms the presence of $\mathrm{Cd}$ and $\mathrm{O}$. The concentrations of these elements are indicated by the peaks, showing clearly that the elements corresponding to the peaks are present in the $\mathrm{CdO}$ thin film deposited the glass substrate. Carbon was considered as contaminant because of its small value in the sample. Raj et al [16] reported the formation of $\mathrm{CdO}$ nano-wires through microwave combustion and confirmed formation of $\mathrm{CdO}$ nanowire with the help of EDAX analysis. They have found that the ratio of atomic concentration is $1: 1$ for $\mathrm{CdO}$ film. The films prepared by thermal evaporation techniques $[17,18]$ exhibit stoichiometric ratio of $\mathrm{Cd}$ to $\mathrm{O}$. So, present work is 
in good agreement with the earlier reports in literature [16-18].

\subsubsection{X-ray Photoelectron Spectroscopy (XPS)} Analysis

The sample V4 was also characterized for X-ray photoelectron spectroscopy as shown in Fig 6. XPS survey scan spectrum of sampleV4 shows that; it consists of $\mathrm{Cd}, \mathrm{O}$ and trace of $\mathrm{C}$ elements. The presence of $\mathrm{C} 1 \mathrm{~s}$ peak is attributed to contamination resulting due to exposure of sample to air prior to XPS analysis [19]. The normalized XPS spectrum of $\mathrm{Cd} 3 \mathrm{~d}$ core level regions is also shown in the Fig.6 along with $\mathrm{O}$ 1s core level regions for sample V4. Narrow scan spectra for cadmium shows well resolved doublets of $\mathrm{Cd} 3 \mathrm{~d}_{5 / 2}$ and $\mathrm{Cd} 3 \mathrm{~d}_{3 / 2}$ components with binding energies $405.61 \pm 0.5 \mathrm{eV}$ and $412.28 \pm 0.5 \mathrm{eV}$, respectively [20]. The $\mathrm{O} 1 \mathrm{~s}$ peak resolved into various components is centered at $532.25 \pm 0.5 \mathrm{eV}, 533.62 \pm 0.5 \mathrm{eV}$ and $536.14 \pm$ $0.5 \mathrm{eV}$. XPS analysis of sample V4 supports the EDAX analysis as mentioned in section 3.3.1.

The optical absorption data was further analyzed to determine band gap of as deposited thin films. To obtain band gap the graph of (ahv) ${ }^{2}$ versus hv was plotted for a typical sample V4 and it is shown in Fig 7 . The band gap energy ' $\mathrm{E}_{\mathrm{g}}$ ' is determined by extrapolating linear portion of the curve to the hv axis [21]. The measured values of the band gap vary from 2.42 to $2.55 \mathrm{eV}$ (not shown). The increase in band gap with increase in solution quantity may be attributed to the increase in crystallinity of the film with increase in film thickness. These results are in good agreement with the results reported by other researchers [22]. Band gap of typical sample V4 is estimated to be $2.45 \mathrm{eV}$ (fig.7.).

\subsection{H2S Gas Sensing Measurements}

Performance of cadmium oxide thin films towards $\mathrm{H}_{2} \mathrm{~S}$ gas sensing, is determined by exposing the film to $\mathrm{H}_{2} \mathrm{~S}$ gas at some constant operating temperature. Before experimentation the sample under test was heated at $300{ }^{\circ} \mathrm{C}$ for some time and then cooled to room temperature. Before passing the gas, sample was allowed to stabilize for electrical resistance for 15 minutes and room temperature resistance was measured and it was taken as Ra.

To obtain the optimum operating temperature, response of $\mathrm{CdO}$ thin film to $\mathrm{H}_{2} \mathrm{~S}$ gas was studied at different operating temperatures under fixed concentration of $\mathrm{H}_{2} \mathrm{~S}$ (200 ppm). Fig. 8 shows the variation of film resistance with time for different operating temperatures. Fig. 8 exhibits that the $\mathrm{CdO}$ shows good sensitivity about $10.12 \%$ at $250{ }^{\circ} \mathrm{C}$. The $\%$ sensitivity was calculated as a function of operating temperature and it is found to be maximum at $250^{\circ} \mathrm{C}$ as shown in Fig 9. This is observed because at low operating temperature, $\mathrm{H}_{2} \mathrm{~S}$ molecules do not have sufficient thermal energy to react with the adsorbed oxygen species at surface and film shows low sensitivity at low operating temperature [23]. However, at higher operating temperatures the adsorbed oxygen gets converted from $\mathrm{O}_{2}^{-}$to $\mathrm{O}^{-}$. The gas sensing reactions that takes place at the surface reported by Shewale et al [24] are :

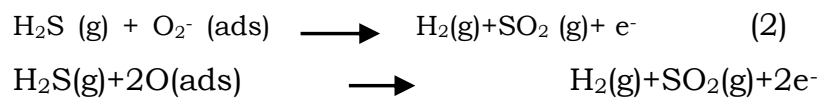

(3)

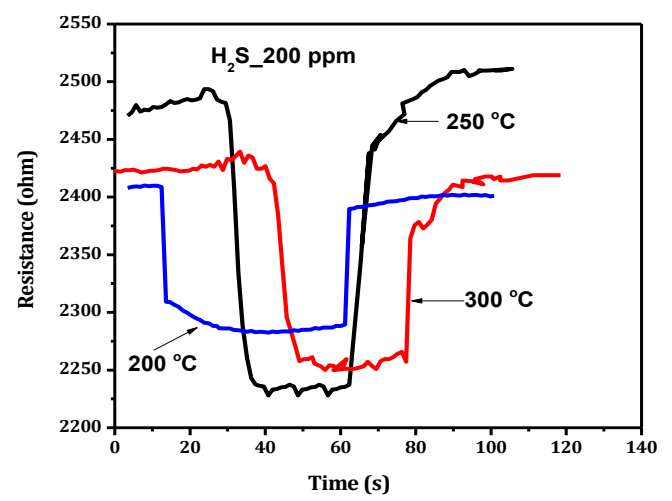

Fig.8: Resistance vs time plots for pure CdO thin film (Sample V4) $\mathrm{H}_{2} \mathrm{~S}$ gas concentrations of $200 \mathrm{ppm}$ at different operating temperature 


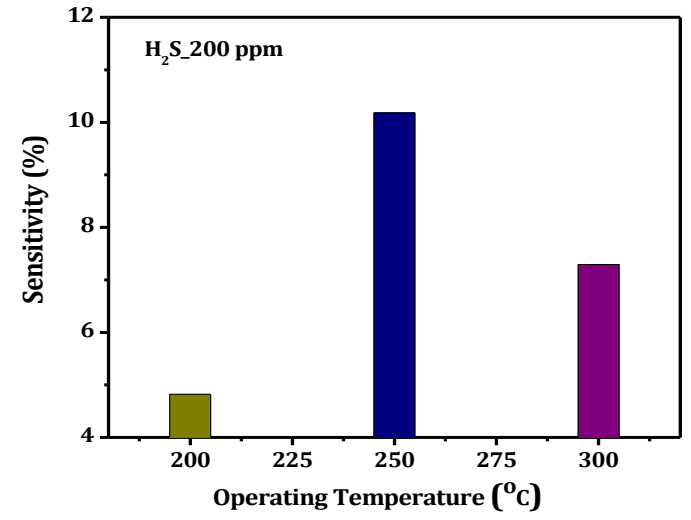

Fig.9: $\mathrm{H}_{2} \mathrm{~S}$ gas sensitivity at different temperatures shown by pure CdO thin film (Sample V4)

The increase in response at $250^{\circ} \mathrm{C}$ may be due to the supply of adequate thermal energy to overcome inter-granular barrier height. The decrease in response at higher temperature $\left(300^{\circ} \mathrm{C}\right)$ may be due to the excess thermal energy that may slow down the process of interaction with oxygen.

\section{CONCLUSION :}

CdO thin films were successfully deposited using spray CVD technique. The films were nanocrystalline in nature with rough surface having granular morphology. As deposited films have transparency up to $83 \%$ in the visible region. The optical band gap is found in the range of 2.42-2.55 $\mathrm{eV}$. The typical sample V4 has band gap of $2.45 \mathrm{eV}$ and is found to be sensitive to $\mathrm{H}_{2} \mathrm{~S}$ gas and showed maximum sensitivity of $\sim 10 \%$ at an operating temperature of $250^{\circ} \mathrm{C}$ under exposure to $200 \mathrm{ppm}$ concentration of $\mathrm{H}_{2} \mathrm{~S}$ gas.

\section{REFERANCE :}

O. Lupan, L. Chow, S. Shishiyanu, E. Monaico, T. Shishiyanu, V. Sontea, B. Roldan Cueny, A. Naitabdi, S. Park and A. Schulte, Mater. Res. Bull. 44 (2009) 63.

J. Tamaki, A. Hayashi, Y. Yamamoto, M. Matsuoka, Sens. Actuators B, 95 (2003) 111.
T. Yamazaki, H. Okumura, C.J. Jin, A. Nakayama, T. Kikuta and N. Nakatani, Vacuum 77 (2005) 237.

G. Korotcenkov, V. Brinzari, J. R. Stetter, I. Blinov and V. Blaja, Sens. Actuators, B 128 (2007) 51 .

R. R. Salunkhe and C. D. Lokhande, Sens. Actuators B, 129 (2008) 345.

V. Kobrinsky, E. Fradkin, V. Lumelsky, A. Rothschild, Y. Komem and Y. Lifshitz, Sens. Actuators B, 148 (2010) 379.

G. Korotcenkov, Mat. Sci. Eng. R, 61 (2008) 1.

X. Fu, J. Liu, T. Han, X. Zhang, F. Meng and J. Liu, Sens. Actuators B, 184 (2013) 260.

R. R. Salunkhe, D. S. Dhawale, D. P. Dubal, and C. D. Lokhande, Sens. Actuators B, 140 (2009) 86.

P. S. Shewale, S. I. Patil, and M. D. Uplane, Semicond. Sci. Tech., 25 (2010) 115008.

$\underline{\text { R. J. Deokate, }} \underline{\text { S. M. Pawar, A.V. Moholkar, }} \underline{\text { V.S. }}$ Sawant, C. A. Pawar, C. H. Bhosale and K. Y. Rajpure, Appl. Surf. Sci. 254 (2008) 2187.

C. H. Bhosale, A.V. Kambale, A.V. Kokate and K. Y. Rajpure, Mat. Sci. Eng. B, 122 (2005) 67.

R. R. Salunkhe, V. R. Shinde and C. D. Lokhande, Sens. Actuators B, 133 (2008) 296.

B. D. Cullity, Elements of X-ray Diffraction, IInd edition, Addison Wesley, Reading MA, (1978) 162.

D. S. Raj, R. Jayaprakash, T. Prakash, S. Kumar, G. Neri and T. Krishnakumar, Appl. Surf. Sci., 266(2013)268.

M. Zaien,N. M. Ahmed and Z. Hassan, Int. J. Electrochem. Sci., 8 (2013) 6988.

M. Zaien,N. M. Ahmed and Z. Hassan, Mater. Sci. Forum, 756 (2013) 54.

P.S. Patil, P.K. Kawar and S. B. Sadale, Electrochim. Acta 50 (2005) 2527.

M. Oztas, Chin. Phys. Lett. 25 (2008) 4090.

A. Ashour, M. A. Kaid, N. Z. El-Sayed and A. A. Ibrahim, Appl. Surf. Sci. 252 (2006) 7844. 
B. J. Lokhande and M.D. Uplane, Appl. Surf. Sci. 167 (2000) 243.

S. Kar, B. N. Pal, S. Chaudhuri and D. Chakravorty, J. Phys. Chem. B 110 (2006) 4605.
P. S. Shewale, G. L. Agawane, S. W. Shin, A. V. Moholkar, J. Y. Lee, J. H. Kim and M. D. Uplane, Sens. Actuators B, 177, (2013) 695.
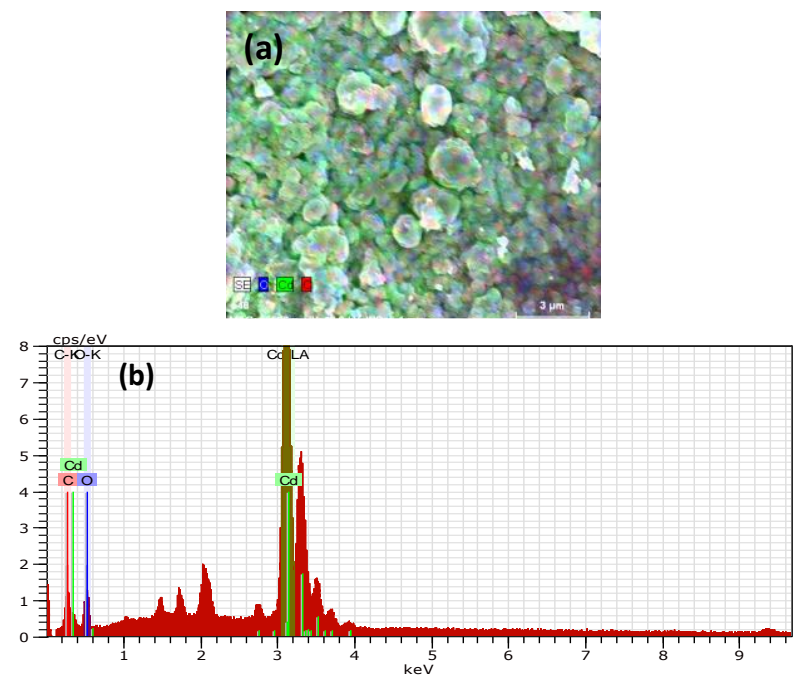

Fig. 5: (a): FESEM image at magnification of X 12,500 and (b) EDAX Analysis of Sample V4.

Table 1: Atomic percent of elements present in sample V4

\begin{tabular}{|c|c|c|c|}
\hline Element & Atomic No. (Z) & Series & At. \% \\
\hline $\mathrm{O}$ & 8 & K-Series & 50.75 \\
\hline $\mathrm{Cd}$ & 48 & L-Series & 49.25 \\
\hline
\end{tabular}

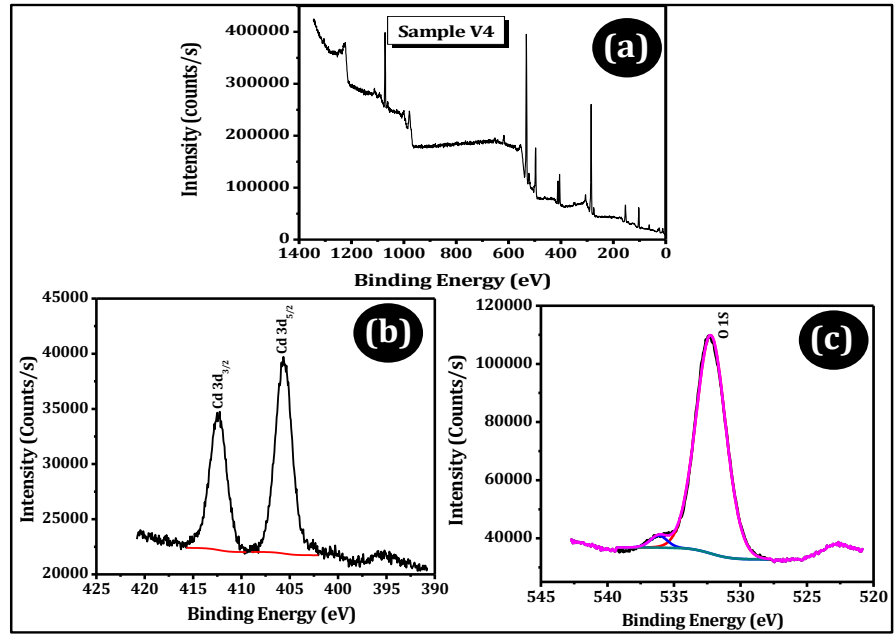

Fig.6: XPS analysis of typical Sample V4 


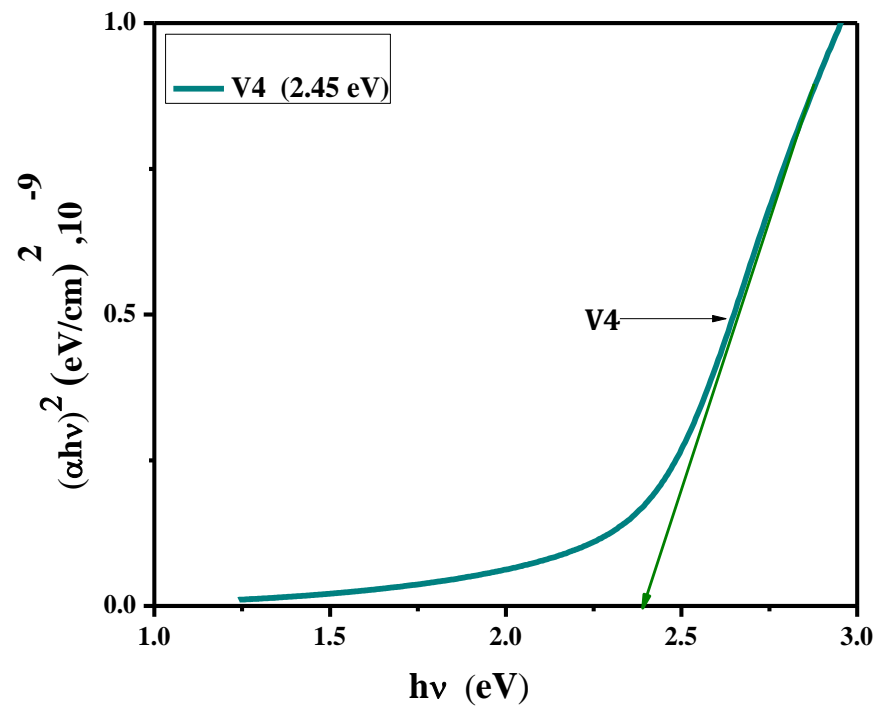

Fig.7: Plot of $(a h v)^{2}$ versus hv for sample V4 